\title{
Conserving biodiversity under climate change: the rear edge matters
}

\author{
Arndt Hampe ${ }^{1 \star}$ and \\ Rémy J. Petit ${ }^{2}$ \\ ${ }^{1}$ Integrative Ecology Group, \\ Estación Biológica de Doñana \\ (CSIC), Apdo. 1056, E-41080 \\ Sevilla, Spain \\ ${ }^{2}$ UMR Biodiversity, Genes and \\ Ecosystems (INRA), 69 route \\ d'Arcachon, F-33612 Cestas \\ Cedex, France \\ ${ }^{*}$ Correspondence: E-mail: \\ arndt@ebd.csic.es
}

\begin{abstract}
Modern climate change is producing poleward range shifts of numerous taxa, communities and ecosystems worldwide. The response of species to changing environments is likely to be determined largely by population responses at range margins. In contrast to the expanding edge, the low-latitude limit (rear edge) of species ranges remains understudied, and the critical importance of rear edge populations as long-term stores of species' genetic diversity and foci of speciation has been little acknowledged. We review recent findings from the fossil record, phylogeography and ecology to illustrate that rear edge populations are often disproportionately important for the survival and evolution of biota. Their ecological features, dynamics and conservation requirements differ from those of populations in other parts of the range, and some commonly recommended conservation practices might therefore be of little use or even counterproductive for rear edge populations.
\end{abstract}

\section{Keywords}

Demography, diversification, extinction, genetic differentiation, glacial refugia, global change, leading edge, peripheral populations, Quaternary, trailing edge.
INTRODUCTION: MARGINAL POPULATIONS, THE LEADING AND THE REAR EDGE

There is now ample evidence that modern climate change is reshuffling the geographic distributions of plant and animal species world-wide (Parmesan \& Yohe 2003). The dynamics of those populations that inhabit the latitudinal margins of the distribution range are likely to be critically important in determining species' responses to expected climate change (e.g. Thomas et al. 2001; Iverson et al. 2004; Travis \& Dytham 2004). Here, we argue that rear edge populations, defined as those populations residing at the current low-latitude margins of species' distribution ranges, are disproportionately important for the long-term conservation of genetic diversity, phylogenetic history and evolutionary potential of species and that their investigation and conservation deserve high priority.

Comparing the behaviour of local populations across species' distribution ranges has a long tradition (Brown et al. 1996). A major paradigm of this research is the 'centreperiphery hypothesis', which predicts that marginal populations are more prone to extinction and genetically less diverse than those from the centre, because they tend to occur in less favourable habitats and at lower and more variable densities (Lawton 1993; Vucetich \& Waite 2003). Although the utility of this paradigm at local to regional scales is generally accepted, recent empirical work has challenged its significance at broad geographical scales (Channell \& Lomolino 1999; Sagarin \& Gaines 2002a,b; Vucetich \& Waite 2003). In particular, phylogeographic surveys show that rangewide patterns of population genetic diversity are usually shaped by past climate-driven range dynamics (Hewitt 2000, 2004) rather than by demo-genetic stochasticity per se, as proposed in the centre-periphery model. As a consequence, marginal rather than central populations commonly harbour the bulk of species' genetic diversity (e.g. Petit et al. 2003; Hewitt 2004). In summary, the utility of the deterministic centre-peripherymodel is limited in the context of range modifications driven by climatic changes.

During the past decade, a more dynamic view of presentday distribution ranges has increasingly been adopted in phylogeography, invasion biology and global change biology, and the demographic and evolutionary processes that accompany species expansions have attracted much attention (e.g. Sakai et al. 2001; Thomas et al. 2001; Petit et al. 2004). In particular, the 'leading edge' model of colonization, which states that range expansions involve mostly populations from the colonization front and are largely controlled by rare long-distance dispersal events followed by 
exponential population growth, has become a central paradigm in phylogeography, as it helps to explain the commonly observed poleward decrease of genetic diversity both within and among populations (Hewitt 1993, 2000).

In contrast, no theoretical study has investigated the behaviour of populations located at eroding range margins following climate change (see below), and there are only a handful of empirical studies addressing this issue. In principle, the behaviour at such distribution edge could range between two extremes: populations could become completely extirpated, resulting in latitudinal displacement of a species' range, or a varying fraction could persist, resulting in a simple expansion of the range into newly favourable regions without concomitant decline at the other extremity. We suggest reserving the term 'trailing edge' for the first situation; populations that inhabit trailing edges should therefore be at most slightly older than other populations of the range. A good example of this situation is provided by some boreal species such as spruce in North America, whose range has entirely shifted since the last ice age (Williams et al. 2004). In contrast, 'stable edges' should refer to situations where at least some populations have persisted in situ at suitable growing sites across Quaternary climatic oscillations, while the species expanded its range into other regions; these stable relict populations can be two or three orders of magnitude older than any populations from the rest of the range and have often persisted in longterm isolation. So far, opinions differ as to the relative importance of these two types of rear edges (Bennett et al. 1991; Davis \& Shaw 2001), but phylogeographic surveys suggest that relict populations exist in a large number of species, particularly whenever mountain ranges are present at low latitudes of current ranges (e.g. Hewitt 2000, 2004; Petit et al. 2003). In what follows, we focus on 'stable' rear edges, given their importance for the conservation of species' biodiversity.

\section{FEATURES OF STABLE REAR EDGE POPULATION S}

Such populations should occur mostly in regions that have provided suitable conditions for species persistence under both cold stage and warm stage conditions (Tzedakis et al. 2002). These regions typically harbour a heterogeneous topography, which allows populations to match suitable climatic conditions by relatively small altitudinal shifts. Under current climatic conditions, extant populations of terrestrial organisms are primarily constrained by water availability, while water temperature and its secondary effects are probably most limiting for aquatic and marine species. In either ecosystem, rear edge populations are typically restricted to particular habitat islands within a matrix of unsuitable landscapes. Figure 1 illustrates some of their most salient features. Rear edge populations are typically small and so isolated that regional population dynamics cannot easily compensate local extinction events. Their successful long-term persistence in spite of fairly small population sizes, at least during interglacial periods, indicates that extinction because of demographic stochasticity has played a relatively minor role (contradicting the centreperiphery-model). However, their small size and prolonged isolation have resulted in reduced within-population genetic diversity (see e.g. Castric \& Bernatchez 2003; Petit et al. 2003; Chang et al. 2004). On the other hand, disproportionately high levels of genetic differentiation are observed among such populations, even between nearby ones, leading to exceptionally high levels of regional genetic diversity (Comps et al. 2001; Castric \& Bernatchez 2003; Hampe et al. 2003; Petit et al. 2003; Martin \& McKay 2004). Note indeed that most of these relict populations have not been the source of major postglacial recolonizations, contrary to common belief, thereby preserving their high genetic distinctiveness (e.g. Bilton et al. 1998; Petit et al. 2003). Furthermore, selection for local adaptation rather than for

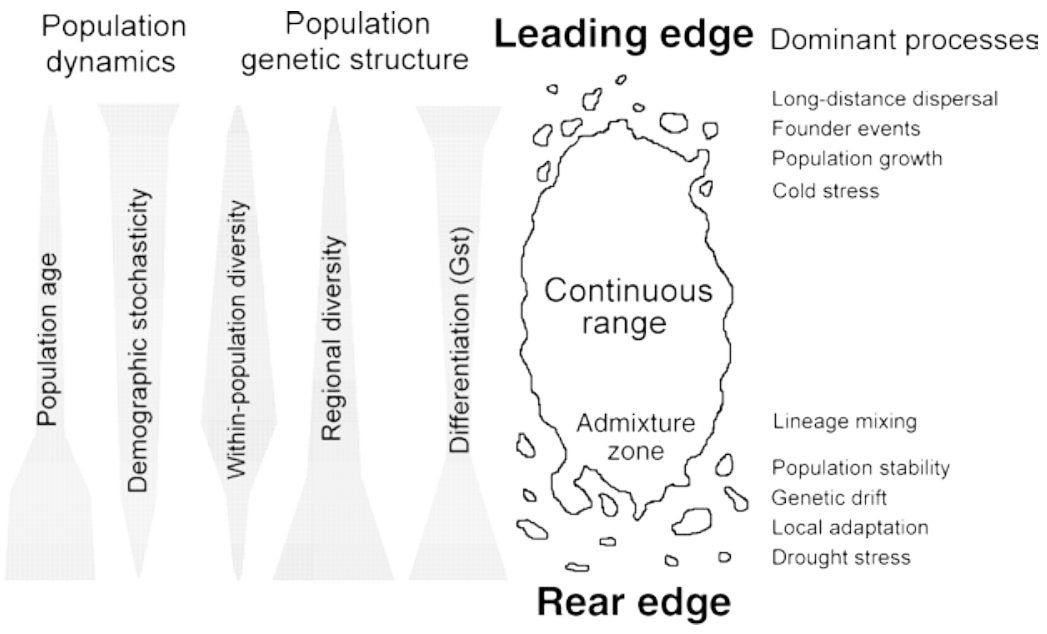

Figure 1 Population features and relevant processes at the leading and the rear edge of species ranges. The width of grey bars shown on the left hand indicates the quantity of features at the corresponding position within the range. 
vagility and generalism is expected in these populations (Dynesius \& Jansson 2000), which can, in association with reduced gene flow, result in the development of remarkably distinct ecotypes (Hampe \& Bairlein 2000; Castric \& Bernatchez 2003; Pérez-Tris et al. 2004).

\section{LONG-TERM IMPORTANCE OF THE REAR EDGE}

Present-day geographic patterns of biodiversity result from the interplay of three population-dynamic processes acting throughout the Quaternary: divergence (ultimately leading to speciation), extinction and migration. The description of migration processes during postglacial range expansions has been a major goal of palaeoecological and, more recently, phylogeographic research. However, patterns observed during interglacial periods have regularly been wiped out at their end, as range contractions have mostly resulted from massive population extinctions at high-latitude range margins, whereas migration towards lower latitudes has apparently been of little importance (Bennett et al. 1991; Jansson \& Dynesius 2002). Consequently, patterns of migration should have had a minor effect on the evolution and maintenance of biodiversity across Quaternary climate oscillation.

In contrast to the individualistic nature of migration processes, Quaternary species extinctions have apparently been remarkably deterministic. Svenning (2003) showed recently, in a thorough analysis of the Northwest European Tertiary tree flora, that only the most climate-tolerant genera were able to cope with Quaternary climate oscillations, whereas cold-sensitive but relatively drought-tolerant genera are now restricted to the southern Mediterranean Basin and the least tolerant genera have completely disappeared from the continent (while they survived in the milder regions of North America and East Asia). This pattern underscores the importance of the long-term persistence of rear edge populations in shaping current biogeographical patterns through its mitigating effect on extinctions. It is probably not limited to temperate latitudes, as the regional richness of plant and vertebrate endemic species worldwide is positively correlated with past climate stability (Jansson 2003).

Rear edge populations should also have played a major role in the diversification of the biota. Many modern species of plants and animals date back to the Tertiary (Hewitt 2000; Willis et al. 2004). Since gradual speciation appears to be a slow process, at least in long-lived taxa, it would seem that only regions that have allowed long-term population persistence through both cold and warm Quaternary stages have some chance of giving birth to new species (Jansson \& Dynesius 2002). In phylogeographic studies, only 'shallow' lineages are generally found at high latitudes compared with much deeper lineages in areas where survival under glacial maximum conditions is probable (Petit et al. 2003; Hewitt
2004). This negative relationship between lineage divergence and latitude is especially strong in regions that have been under the most direct influence of Quaternary glaciations, but it is not exclusive to this part of the globe (Martin \& McKay 2004).

Hence, populations that inhabit present-day rear edges of species ranges appear to have played a key role for the maintenance of biodiversity throughout the Quaternary. A thorough evaluation of their current performance and viability appears therefore of utmost importance for successful conservation of intra- and interspecific biodiversity under anticipated global change.

\section{RESEARCH ON REAR EDGE POPULATIONS}

We conducted a bibliometric study to identify current trends in research on peripheral populations. The ISI Web of Science bibliographic database (1945 to October 2004) was screened in a heuristic search using the combined terms 'population', 'range' and 'margin', as well as different synonyms. (The combination was necessary to exclude studies from other disciplines and retain a manageable sample size.) Original studies that focused on global-scale range margins were considered only when they provided a minimum amount of ecological information, thereby excluding studies that merely reported new peripheral populations of a given taxon. Papers were classified according to the principal focus of the study (theoretical, genetic or ecological), their consideration or not of past or future dynamics and the type of study organism and ecosystem.

We found a total of 382 studies dealing with range margins, most of them published in recent years (Fig. 2). Most studies (86\%) took place in terrestrial ecosystems (vs. $4 \%$ for aquatic and $5 \%$ for marine ecosystems). Latitudinal range margins were investigated in 300 papers, while the rest reported on other situations (mostly recent invasions, other core-periphery situations or modelling exercises). An increasing fraction of studies has considered the dynamic nature of species ranges, although it is still ignored in many recent investigations (Fig. 2). The vast majority of research has taken place in Europe or North America. There has been a strong bias towards high-latitude range margins (86\% of studies), whereas only a relatively minor number of studies dealt with rear edge populations: 27 with static and 20 with dynamic range perspectives, plus 16 surveys that included both range margins. No theoretical or modelling exercise has so far explicitly explored the behaviour of rear edge populations, be they of the 'stable' or the 'trailing' type (Fig. 2; cf. Travis \& Dytham 2004 for a related study). Likewise, no experimental work or long-term data series and very few palaeoecological analyses of the fossil record (but see Tzedakis et al. 2002) have focused on low-latitude range margins, in contrast to the opposite periphery. Virtually all 


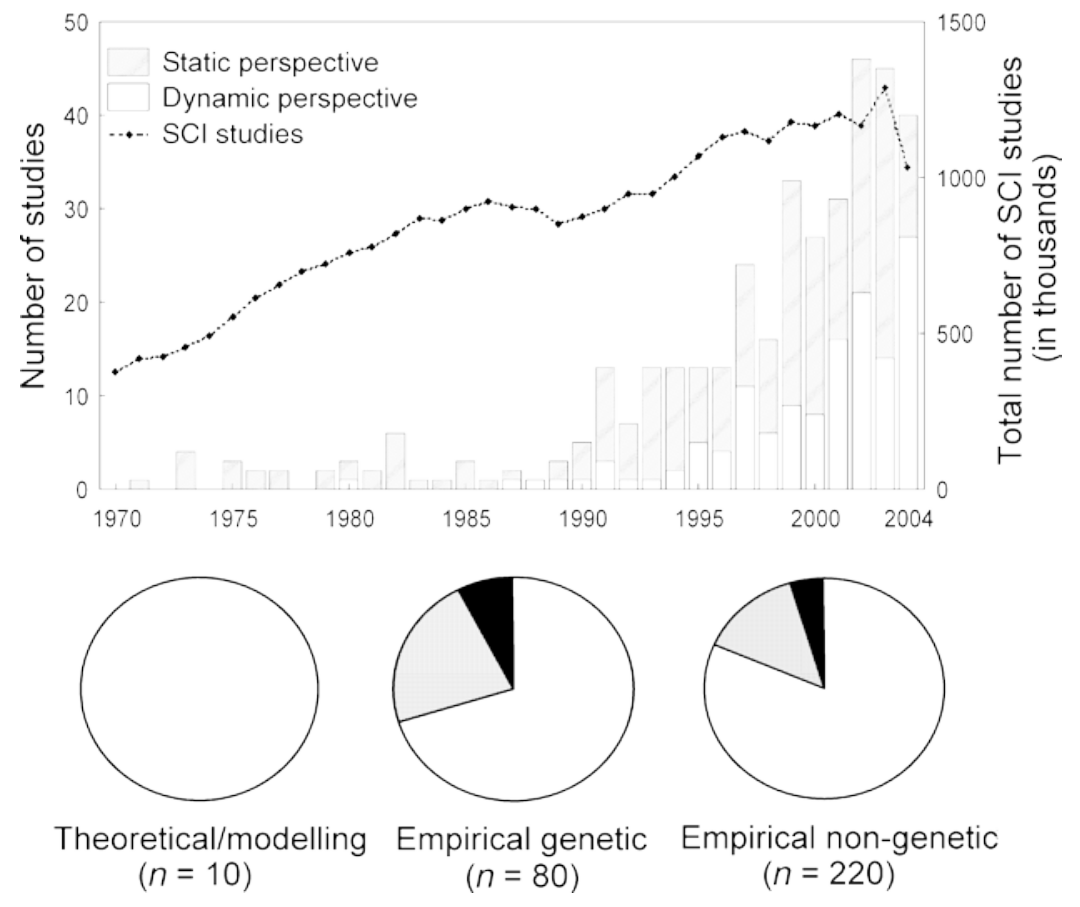

Figure 2 Development and main fields of research on peripheral populations. The upper graph illustrates the number of papers on this topic published annually since 1970 , which are compared with the total number of publications included in the ISI Science Citation Index (SCI). Only those papers that had appeared in the SCI database by October 2004 are included (i.e. $<75 \%$ of the total for that year). Pie charts show the fraction of theoretical and different types of empirical studies that have been carried out at high-latitude (white), at low-latitude (black) and at both range margins (grey), respectively. available information on rear edge population dynamics comes therefore from snapshot studies that have either been carried out along climatic gradients (e.g. García et al. 1999; Epps et al. 2004) or have extrapolated results of short-term studies on long-term series of weather data (e.g. Hódar et al. 2003; Hampe 2005). A range-dynamic view has largely remained the domain of phylogeographic research, while few ecological field studies have been designed to assess range dynamics at the rear edge (in stark contrast with range margins at high latitudes or altitudes). The earliest notable exception was Hamburg \& Cogbill's (1988) investigation of the recent decline of red spruce (Picea rubens Sarg.) in the Eastern USA. Since then, an increasing number of studies have started to document and analyse recent altitudinal range shifts at the low-latitude range margin of species because of extinction of the lowermost populations (e.g. Parmesan 1996; Fisher 1997; Pounds et al. 1999; Peñuelas \& Boada 2003; Epps et al. 2004; Lesica \& McCune 2004).

\section{PRESENT AND FUTURE PERFORMANCE OF REAR EDGE POPULATIONS}

Virtually all field ecological research has been conducted on perennial plants. Studies have largely focused on reproduction and initial recruitment, as these are the most dynamic and variable stages of the regeneration cycle and therefore most amenable to short-term ecological studies. Negative effects of recent climate change on rear edge populations have been identified for the Eurasian shrub Frangula alnus
Miller, whose seed production is greatly affected by the timing of the onset of summer drought, which has advanced significantly over the past few decades (Hampe 2005). In contrast, increasing winter temperatures appear to depress reproductive success in southern peripheral populations of Pinus sylvestris L., as they favour outbreaks of the pine processionary caterpillar, Thaumetopoea pityocampa Schiff (Hódar et al. 2003). Studies on initial plant recruitment have usually observed that water stress during summer reduces seedling survival to almost zero in the most peripheral populations, which appear to be virtually remnant under current climatic conditions (García et al. 1999; Peñuelas \& Boada 2003; Castro et al. 2004). However, for long-lived organisms, demographic trends of rear edge populations cannot simply be inferred from their current recruitment rates (e.g. Eriksson 1996; Clark et al. 1999). Instead changes of adult mortalities could be much better indicators, but these have scarcely been monitored. A notable exception is the work of Allen \& Breshears (1998) who reported a massive dieback of P. ponderosa Douglas ex Lawson \& C. Lawson in a New Mexican woodland ecotone during a recent severe drought period. However, this case exemplifies a classical 'trailing edge' situation. Instead, the existence of stable rear edges could be particularly common in those plant or animal species whose populations are able to endure long periods without recruitment (by long life span, clonal growth, persistent seed banks etc.; cf. García \& Zamora 2003). Unfortunately, too few empirical studies exist at present to test this hypothesis. Finally, it would be 
interesting to test if climate change affected rear edge population performance primarily through direct abiotic limitations, such as drought in terrestrial or water temperature in aquatic systems, or via their effects on biological interactions, such as competition or the breakup of mutualistic relationships (e.g. Loehle 1998).

Altogether, ecological research on rear edge populations is still very limited, making predictions hazardous. At the same time, predictions based on climate envelope modelling (e.g. Thomas et al. 2004) are becoming commonplace and these seem to leave little long-term prospects for rear edge populations, despite observations on the importance and historical continuity of many rear edge populations discussed in the preceding paragraphs. In fact, work on current impacts of global change indicates greater stability of lowlatitude than of high-latitude range margins: for instance, during the 20th century, 34\% of the non-migratory butterfly species surveyed by Parmesan et al. (1999) had stable highlatitude distribution edges compared with $72 \%$ that had stable low-latitude edges. The authors suggest that the greater average stability of low-latitude range limits is possibly not because of climatic factors but to biotic ones and to the heterogeneous topography in rear edge populations that offers a greater diversity of climatic 'niches'. It seems thus that (stable) rear edges might not disappear as readily as forecasted by bioclimate envelope models (e.g. Skov \& Svenning 2004; Thomas et al. 2004). Indeed, such models make a number of unrealistic assumptions, particularly so for rear edge populations (Loehle \& LeBlanc 1996; Loehle 1998; Thuiller et al. 2004). For instance, species' current ranges are assumed to be in equilibrium with their environment and to reflect primarily climatic tolerance, whereas other factors, such as dispersal limitation or interactions with other organisms, are often neglected (Iverson et al. 2004; Svenning \& Skov 2004; Thomas et al. 2004). Perhaps most importantly in the context of rear edges, bioclimate envelope models rely mostly on climate data derived from global circulation models and ignore that regional-scale climate changes can be buffered locally by topographic heterogeneity. In summary, two visions of the future of rear edge populations currently coexist, ranging between predictions of complete disappearance based on modelling and more optimistic expectations based on past persistence. A more balanced view will probably emerge once more research will have been conducted on these populations.

\section{RESEARCH AND CONSERVATION NEEDS}

We are only beginning to understand the biological implications of past and ongoing range shifts on species' genetic constitution and evolutionary potential (e.g. Davis \& Shaw 2001; Petit et al. 2004), and bridging both large-scale and local-scale perspectives is required to appreciate the character and conservation needs of rear edge populations, a difficult exercise. Palaeoecological studies are usually of little help, as their geographical resolution is generally too coarse to detect the historical existence of small relict populations. Furthermore, 'relict hotspots' - areas that harbour rear edge populations of many species - are commonly located in regions of the world where the socio-economic situation limits research activities. As these relict hotspots often coincide with centres of high biodiversity and endemism, other organisms will often have monopolized most resources. Accordingly, the value of relict populations at the low-latitude margins of many species' distribution ranges has remained largely unperceived by conservation biologists. Some glacial relicts have been included in regional or national red lists, but neither research nor conservation programs seem to have been dedicated to rear edge populations per se (although Lesica \& Allendorf (1995) have considered the conservation value of peripheral populations in general). Here, we outline three areas in which further development of research and conservation measures appears particularly necessary.

(1) Exploratory surveys should identify further centres of relict diversity. Outside Europe and North America our knowledge about the location of glacial refugia is still very fragmentary (Noss 2001; Hewitt 2004). Relicts hotspots should be concentrated in a limited number of regions around the globe that have allowed survival of many species during both Quaternary cold and warm stages in particular wet and/or cool habitats. The typically small size of these sites should render their detection difficult but could facilitate subsequent conservation measures. On the other hand, it makes them prone to human disturbance, particularly in arid regions where human water demands and browsing by cattle represent serious threats (e.g. Danin 1999; García et al. 1999).

(2) The performance of rear edge populations under changing environmental conditions should become a focus of interdisciplinary research, by integrating demographic and genetic work with modelling approaches and with community ecology. So far, almost all research has focused on temperate perennial plants, and investigation of a broader spectrum of organisms, communities and biomes is clearly needed. Long-term experimental studies are required that distinguish climate effects from other factors, such as habitat fragmentation, genetic load in small populations or biotic interactions. For instance, competition with surrounding communities (or invasive aliens) appears to accelerate the breakdown of 'islands' of relict vegetation (Pounds et al. 1999; Peñuelas \& Boada 
2003), which might otherwise be more resistant to direct climate effects. However, species interactions could also have the opposite effect, since facilitation tends to increase under water stress (cf. Danin 1999; Castro et al. 2004), allowing persistence of a given species in areas where simple models predict that it cannot survive. Realistic predictions of future rear edge population performance requires the development of models that can integrate population dynamics, ecosystem processes and climate trends at landscape to regional scales (Hannah et al. 2002).

(3) Appropriate conservation strategies need to be designed that consider the peculiarities of rear edge populations. For instance, the particular genetic structure of rear edge populations requires conservation strategies directed towards the detection and maintenance of the greatest possible number of local populations, regardless of their size or performance, instead of focusing on the most viable core populations. Likewise, improvement of landscape connectivity is commonly considered essential to allow species to match climate changes by shifting their range (e.g. Noss 2001; Hannah et al. 2002; Thomas et al. 2004), but it would be of little use at stable rear edges and might even be counterproductive, if it enhances competition with surrounding communities or promotes invasion by aliens. Hence, specific conservation measures will have to be identified to effectively preserve these relict populations.

\section{ACKNOWLEDGEMENTS}

Comments from Keith Bennett, Jorge Castro, Emmanuel Corcket, Alain Franc, John Pannell, Juli Pausas and two anonymous referees greatly helped improve an earlier version of this manuscript. A.H. received support by research grants PB98-1144, BOS2002-01162 and REN2003-00273 from the Spanish Ministry of Education and Science and R.J.P from the Institut Français de la Biodiversité.

\section{REFERENCES}

Allen, C.D. \& Breshears, D.D. (1998). Drought-induced shift of a forest-woodland ecotone: rapid landscape response to climate variation. Proc. Natl. Acad. Sci. U.S.A., 95, 14839-14842.

Bennett, K.D., Tzedakis, P.C. \& Willis, K.J. (1991). Quaternary refugia of north European trees. J. Biogeogr., 18, 103-115.

Bilton, D.T., Mirol, P.M., Mascheretti, S., Fredga, K., Zima, J. \& Searle, J.B. (1998). Mediterranean Europe as an area of endemism for small mammals rather than a source for northwards postglacial colonization. Proc. R. Soc. Lond. B, 265, 1219-1226

Brown, J.H., Stevens, G.C. \& Kaufman, D. M. (1996). The geographic range: size, shape, boundaries, and internal structure. Annu. Rev. Ecol. Syst., 27, 597-623.
Castric, V. \& Bernatchez, L. (2003). The rise and fall of isolation by distance in the anadromous brook charr (Salvelinus fontinalis Mitchill). Genetics, 163, 983-996.

Castro, J., Zamora, R., Hódar, J.A. \& Gómez, J.M. (2004). Seedling establishment of a boreal tree species (Pinus sylvestris) at its southernmost distribution limit: consequences of being in a marginal Mediterranean habitat. J. Ecol., 92, 266277.

Chang, C.S., Kim, H., Park, T.Y. \& Maunder, M. (2004). Low levels of genetic variation among southern peripheral poulations of the threatened herb, Leontice microrhyncha (Berberidaceae) in Korea. Biol. Conserv., 119, 387-396.

Channell, R. \& Lomolino, V. (1999). Dynamic biogeography and conservation of endangered species. Nature, 403, 84-86.

Clark, J.S., Beckage, B. Camill, P., Cleveland, B. HilleRisLambers, J., Lichter, J. et al. (1999). Interpreting recruitment limitation in forests. Am. J. Bot., 86, 1-16.

Comps, B., Gömöry, D., Letouzey, J., Thiébaut, B. \& Petit, R.J. (2001). Diverging trends between heterozygosity and allelic richness during postglacial colonization in the European beech. Genetics, 157, 389-397.

Danin, A. (1999). Desert rocks as plant refugia in the Near East. Bot. Rev., 65, 93-170.

Davis, M.B. \& Shaw, R.G. (2001). Range shifts and adaptive responses to Quaternary climate change. Science, 292, 673-679.

Dynesius, M. \& Jansson, R. (2000). Evolutionary consequences of changes in species' geographical distributions driven by Milankovitch climate oscillations. Proc. Natl. Acad. Sci. U.S.A., 97, 9115-9120.

Epps, C.W., McCullough, D.R., Wehausen, J.D., Bleich, V.C. \& Rechel, J.L. (2004). Effects of climate change on population persistence of desert-dwelling mountain sheep in California. Conserv. Biol., 18, 102-113.

Eriksson, O. (1996). Regional dynamics of plants: a review of evidence for remnant, source-sink and metapopulations. Oikos, 77, 248-258.

Fisher, M. (1997). Decline in the juniper woodlands of Raydah reserve in southwestern Saudi Arabia: a response to climate changes? Gl. Ecol. Biogeogr. Lett., 6, 387-396.

García, D. \& Zamora, R. (2003). Persistence, multiple demographic strategies and conservation in long-lived Mediterranean plants. J. Veg. Sci., 14, 921-926.

García, D., Zamora, R., Hódar, J.A. \& Gómez, J.M. (1999). Age structure of Juniperus communis L. in the Iberian Peninsula: conservation of remnant populations in Mediterranean mountains. Biol. Conserv., 87, 215-220.

Hamburg, S.P. \& Cogbill, C.V. (1988). Historical decline of red spruce populations and climatic warming. Nature, 331, 428431

Hampe, A. (2005). Fecundity limits in Frangula alnus (Rhamnaceae) relict populations at the species' southern range margin. Oecologia. Doi: 10.1007/s00442-004-1811-0.

Hampe, A. \& Bairlein, F. (2000). Modified dispersal-related traits in disjunct populations of bird-dispersed Frangula alnus (Rhamnaceae): a result of its Quaternary distribution shifts? Ecography, 23, 603-613.

Hampe, A., Arroyo, J., Jordano, P. \& Petit, R.J. (2003). Rangewide phylogeography of a bird-dispersed Eurasian shrub: contrasting Mediterranean and temperate glacial refugia. Mol. Ecol., 12, 3415-3426. 
Hannah, L., Midgley, G.F. \& Millar, D. (2002). Climate changeintegrated conservation strategies. Gl. Ecol. Biogeogr., 11, 485495.

Hewitt, G.M. (1993). Postglacial distribution and species substructure: lessons from pollen, insects and hybrid zones. In: Evolutionary Patterns and Processes (eds Lees, D.R. \& Edwards, D. ). Linnean Society Symposium Series 14, Academic Press, London, pp. 97-123.

Hewitt, G.M. (2000). The genetic legacy of the ice ages. Nature 405, 907-913.

Hewitt, G.M. (2004). Genetic consequences of climatic changes in the Quaternary. Phil. Trans. R. Soc. Lond. B 359, 183-195.

Hódar, J.A., Castro, J. \& Zamora, R. (2003). Pine processionary caterpillar Thaumetopoea pityocampa as a new threat for relict Mediterranean Scots pine forests under climatic warming. Biol. Conserv., 110, 123-129.

Iverson, L.R., Schwartz, M.W. \& Prasad, A.M. (2004). How fast and far might tree species migrate in the eastern United States due to climate change? Gl. Ecol. Biogeogr., 13, 209-219.

Jansson, R. (2003). Global patterns of endemism explained by past climatic change. Proc. R. Soc. Lond. B 270, 583-590.

Jansson, R. \& Dynesius, M. (2002). The fate of clades in a world of recurrent climatic change: Milankovitch oscillations and evolution. Annu. Rev. Ecol. Syst., 33, 741-777.

Lawton, J.H. (1993). Range, population abundance and conservation. Trends Ecol. Evol., 8, 409-413.

Lesica, P. \& Allendorf, F.W. (1995). When peripheral populations are valuable for conservation. Conserv. Biol., 9, 753-760.

Lesica, P. \& McCune, B. (2004). Decline of arctic-alpine plants at the southern margin of their range following a decade of climatic warming. J. Veg. Sci., 15, 679-690.

Loehle, C. (1998). Height growth rate tradeoffs determine northern and southern range limits for trees. J. Biogeogr., 25, 735-742.

Loehle, C. \& LeBlanc, D. (1996). Model-based assessments of climate change effects on forests: a critical review. Ecol. Model., 90, 1-31.

Martin, P.R. \& McKay, J.K. (2004). Latitudinal variation in genetic divergence of populations and the potential for future speciation. Evolution, 58, 938-945.

Noss, R.F. (2001). Beyond Kyoto: forest management in a time of rapid climate change. Conserv. Biol., 15, 578-590.

Parmesan, C. (1996). Climate and species' range. Nature, 382, 765766.

Parmesan, C. \& Yohe, G. (2003). A globally coherent fingerprint of climate change impacts across natural systems. Nature, 421, 3742.

Parmesan, C., Ryrholm, N., Stefanescu, C., Hill, J.K., Thomas, C.D., Descimon, H. et al. (1999). Poleward shifts in geographical ranges of butterfly species associated with regional warming. Nature, 399, 579-583.

Peñuelas, J. \& Boada, M. (2003). A global change-induced biome shift in the Montseny mountains (NE Spain). Gl. Change Biol., 9, 131-140.

Pérez-Tris, J., Bensch, S., Carbonell, R., Helbig, A.J. \& Tellería, J.L. (2004). Historical diversification of migration patterns in a passerine bird. Evolution, 58, 1819-1832.

Petit, R.J., Aguinagalde, I., de Beaulieu, J.L., Bittkau, C., Brewer, S., Cheddadi, R. et al. (2003). Glacial refugia: hotspots but not melting pots of genetic diversity. Science, 300, 1563-1565.
Petit, R.J., Bialozyt, R., Garnier-Géré, P. \& Hampe, A. (2004). Ecology and genetics of tree invasions: from recent introductions to Quaternary migrations. For. Ecol. Manage., 197, 117-137.

Pounds, J.A., Fogden, M.P.L. \& Campbell, J.H. (1999). Biological response to climate change on a tropical mountain. Nature, 398, 611-615.

Sagarin, R.D. \& Gaines, S.D. (2002a). The 'abundant center' distribution: to what extent is it a biogeograpical rule? Ecol. Lett., 5, 137-147.

Sagarin, R.D. \& Gaines, S.D. (2002b). Geographical abundance distributions of coastal invertebrates: using one-dimensional ranges to test biogeographic hypotheses. J. Biogeogr., 29, 985-997.

Sakai, A.K., Allendorf, F.W., Holt, J.S., Lodge, D.M., Molofsky, J., With, K.A. et al. (2001). The population biology of invasive species. Annu. Rev. Ecol. Syst., 32, 305-332.

Skov, F. \& Svenning, J.C. (2004). Potential impact of climatic change on the distribution of forest herbs in Europe. Ecography, 27, 366-380.

Svenning, J.C. (2003). Deterministic Pliocene-Pleistocene extinctions in the European cool-temperate tree flora. Ecol. Lett., 6, 646-653.

Svenning, J.C. \& Skov, F. (2004). Limited filling of the potential range in European tree species. Ecol. Lett., 7, 565-573.

Thomas, C.D., Bodsworth, E.J., Wilson, R.J., Simmons, A.D., Davies, Z.G., Musche, M. et al. (2001). Ecological and evolutionary processes at expanding range margins. Nature, 411, 577581.

Thomas, C.D., Cameron, A., Green, R.E., Bakkenes, M., Beaumont, L.J., Collingham, Y.C. et al. (2004). Extinction risk from climate change. Nature, 427, 145-148.

Thuiller, W., Brotons, L., Araujo, M.B. \& Lavorel, S. (2004). Effects of restricting environmental range of data to project current and future species distributions. Ecography, 27, 165-172.

Travis, J.M.J. \& Dytham, C. (2004). A method for simulating patterns of habitat availability at static and dynamic range margins. Oikos, 104, 410-416.

Tzedakis, P.C., Lawson, I.T., Frogley, M.R., Hewitt, G.M. \& Preece, R.C. (2002). Buffered tree population changes in a quaternary refugium: evolutionary implications. Science, 297, 2044-2047.

Vucetich, J.A. \& Waite, T.A. (2003). Spatial patterns of demgraphy and genetic processes across the species' range: null hypotheses for landscape conservation genetics. Conserv. Gen., 4, 639-645.

Williams, J.W., Shuman, B., Webb, III T, Bartlein, P.J. \& Leduc, P.L. (2004). Late Quaternary vegetation dynamics in North America: scaling from taxa to biomes. Ecol. Monogr., 74, 309-334.

Willis, K.J., Bennett, K.D. \& Walker, D. (2004). The evolutionary legacy of the Ice Ages - Introduction. Phil. Trans. R. Soc. Lond. B, 359, 157-158.

Editor, Francesca Cortufo

Manuscript received 16 December 2004

First decision made 19 January 2005

Manuscript accepted 24 January 2005 